\title{
VULNERABILIDADES, TRABALHADORES E CASAS DE FARINHA: Cenário de riscos no agreste de Pernambuco
}

\author{
Antônio Pacheco de Barros Júnior ${ }^{1 *}$, Werônica Meira de Souza ${ }^{2}$, Maria do Socorro Bezerra de Araújo ${ }^{3}$
}

\author{
${ }^{1}$ Doutorando do Programa de Pós-Graduação em Desenvolvimento e Meio Ambiente (PRODEMA) da Universidade Federal de Pernambuco (UFPE). \\ ${ }^{2}$ Orientadora e professora do Departamento da Unidade Acadêmica de Garanbuns (UAG) da Universidade Federal Rural de Pernambuco (UFRPE) e do \\ Programa de Pós-Graduação em Desenvolvimento e Meio Ambiente (PRODEMA) da Universidade Federal de Pernambuco (UFPE). \\ ${ }^{3}$ Coorientadora e professora do Departamento de Ciências Geográficas (DCG) da Universidade Federal de Pernambuco (UFPE) e do Programa de Pós- \\ Graduação em Desenvolvimento e Meio Ambiente (PRODEMA) da Universidade Federal de Pernambuco (UFPE). \\ *Autor para correspondência: pachecogeoambiental@hotmail.com
}

Recebido em 06 de novembro de 2016. Aceito em 03 de maio de 2018. Publicado em 28 de dezembro de 2018.

Resumo - A vulnerabilidade dos trabalhadores nas casas de farinha é uma situação que pode variar de acordo com as possibilidades sociais, econômicas e ambientais. As casas de farinha envolvem uma quantidade considerável de trabalhadores no processo de beneficiamento da mandioca, onde são observadas condições relacionadas aos riscos e ao comprometimento da qualidade de vida. O objetivo desse trabalho foi quantificar o grau de vulnerabilidade dos trabalhadores em 17 (dezessete) casas de farinha no Município de Lajedo no Agreste de Pernambuco. A metodologia contemplada envolveu as seguintes etapas: levantamento bibliográfico, caracterização da área de estudo, interpretação de dados cartográficos, aplicação de entrevistas, registro fotográfico, análise e organização dos dados. Os resultados obtidos indicaram que os trabalhadores das casas de farinha apresentam altos índices de vulnerabilidade. A omissão do Estado no fomento de políticas públicas deixa esses trabalhadores sobrecarregados não conseguindo romper com o meio em que estão inseridos.

Palavras-chave: Indústria da Farinha; Operário; Risco Ocupacional.

\section{Vulnerability, workers and “Flour houses”: risk scenario in agreste of Pernambuco}

ABSTRACT - The vulnerability of workers in flour houses is a situation that can vary according to social, economic and environmental possibilities. Flour houses involve a considerable number of workers in the process of cassava beneficiation, where conditions related to risks and quality of life are observed. The objective of this study was to quantify the degree of vulnerability of workers in seventeen (17) flour houses in the municipality of Lajedo, in the Agreste of Pernambuco. The methodology addressed involved the following steps: bibliographic survey, characterization of the study area, interpretation of cartographic data, application of interviews, photographic record, analysis and data organization. The results indicate that workers in flour houses present high levels of vulnerability. The State's omission to foster public policies leaves these overworked workers unable to break with the environment in which they are inserted.

Keywords: Flour Houses; Worker; Occupational Risk.

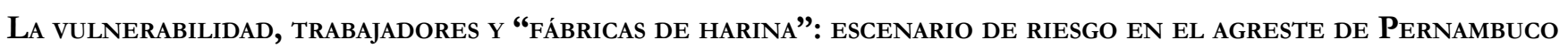

REsumen - La vulnerabilidad de los trabajadores en las fábricas de harina es una situación que puede variar de acuerdo con las posibilidades sociales, económicas y ambientales. Las fábricas de harina involucran una cantidad considerable de trabajadores en el procesamiento de la mandioca, donde se observan condiciones relacionadas con los riesgos y el compromiso de la calidad de vida. El objetivo de este trabajo fue cuantificar el grado de vulnerabilidad de los trabajadores en 17 (diecisiete) fábricas de harina en el Municipio de Lajedo en el Agreste de Pernambuco. La metodología utilizada involucró las siguientes 
etapas: investigación bibliográfica, caracterización del área de estudio, interpretación de datos cartográficos, aplicación de encuestas, registro fotográfico, análisis y organización de los datos. Los resultados obtenidos indicaron que los trabajadores de las fábricas de harina presentan altos índices de vulnerabilidad. La omisión del Estado en el fomento de políticas públicas sobrecarga a esos trabajadores, lo que no les permite romper con el medio en que están insertados.

Palabras-Clave: Industria de la Harina; Trabajador; Riesgos Laborales.

\section{INTRODUÇÃO}

A casa de farinha nasceu, provavelmente, devido ao aumento da população estrangeira -ibéricos e africanos - na porção litorânea das terras do povo tupi. Com muito mais pessoas famintas na terra dos amerígenas, a solução encontrada pelos portugueses foi criar uma engenhoca, a partir da tecnologia indígena, que sistematizasse a produção em maior quantidade de um dos gêneros mais importantes que ao alimentar os homens nutria a saga da colonização por mais de três séculos (Marcena 2012).

Sobre o surgimento das casas de farinha, Andrade (2011, p. 105) assevera:

[...] Sintomático é que ainda hoje, na região da Mata e do Litoral Oriental, a fabricação de farinha se faça pelos mesmos processos da época colonial; a descrição de uma "casa de farinha" feita por Nieuhof, em pleno domínio holandês, identifica-a como as casas de farinha existentes nas "grotas" e nas "chãs" dos nossos antigos engenhos. Enquanto a fabricação do açúcar evoluiu desde o engenho de bois até as grandes usinas que moem anualmente mais de um milhão de sacos de açúcar, a casa de farinha continua muitas vezes a ser movida a força humana. Apesar de sua importância, foi uma cultura relegada a um plano secundário, sempre desprovida de proteção e sempre descuidada a ponto de a sua falta ter sido frequentemente assinalada em toda a história nordestina, falta que estava a dificultar e a piorar cada vez mais o regime alimentar, por si já deficiente, de moradores e escravos.

Conforme se detrai das palavras do autor, o processo de produção da farinha da mandioca contribuiu pela fixação do homem a terra, ajudou a desenvolver a economia do período colonial tendo em vista ter participado da dieta alimentar das pessoas. "A mandioca tem sido desde tempos imemoriais, uma das mais importantes culturas do sistema agrícola tropical, constituindo-se numa das principais fontes de energia alimentar" (Camargo 1985, p.11).

$\mathrm{Na}$ época do Brasil Colônia, no século XVI, a fabricação da farinha de mandioca, acontecia em métodos rudimentares pelos indígenas: ralavam-nas pelo atrito de espinhos, dentes de animais, cascas de ostras. Espremia a massa da mandioca a mão e para deixar a massa quase seca por meio da compressão do cilindro de palha (Cascudo 2011).

A mandioca tem destaque pela sua riqueza extrema em carboidratos, estando à frente do arroz, do milho e da cana-de-açúcar. O tubérculo em questão apresenta um diferencial produtivo de grande relevância seja em relação a sua lavoura, seja em relação aos produtos comercializados e derivados dela. O beneficiamento da mandioca ocorre no Nordeste do Brasil, de forma artesanal, em comunidade produtiva denominada casa de farinha, tendo, no uso desse modelo, um dos principais entraves no que tange à comercialização e à abertura competitiva no mercado (Soares 2007).

No que tange aos tipos de casas de farinha no nordeste brasileiro, Sena (2006, p. 104) comentou:

A casa de farinha tradicional, também conhecida como manual, é assim denominada tendo em vista não possuir quaisquer equipamentos modernos, sendo os processos de trituração de raízes, a prensagem, a desintegração da massa prensada e a torrefação realizados manualmente. Já a modernizada possui algumas 
"inovações", a exemplo da utilização de motor (a gasolina, a diesel ou elétrico) no processo de trituração das raízes. As demais etapas são realizadas manualmente. A casa de farinha eletrificada constitui-se de uma estrutura mais modernizada, dotada de quase todas as etapas de processamento movidas a eletricidade (exceto o descascamento das raízes, que ainda é realizado manualmente), inclusive a torrefação, a qual é realizada num grande forno de ferro dotado de pás de madeira movimentadas por uma engrenagem movida a eletricidade. Existem modelos onde até o ensacamento da farinha é mecanizado.

De acordo com Barros Júnior, Souza e Araújo (2016, p.27), as casas de farinha são empreendimentos, geralmente, de pequeno porte, rústicos, edificações antigas, em péssimo estado de conservação, o que, ao longo do tempo, tem causado grandes impactos ambientais. Os mesmos autores destacam a importância social e econômica da cadeia produtiva da farinha, pois emprega um número significativo de pessoas em todas as fases de produção, principalmente a população de baixa renda, que buscam nessa atividade um meio de sobrevivência.

No que tange à presença das casas de farinha no estado de Pernambuco, os autores Barros Júnior, Pacheco e Cardoso (2016, p. 398) citam que:

i) região de desenvolvimento do Araripe, município de Araripina; ii) região de desenvolvimento Mata Sul, representado por Pombos; iii) região de desenvolvimento Mata Norte, compreendendo o município de Glória do Goitá; iv) região do Agreste Setentrional, em Feira Nova e v) região do Agreste Meridional, nos municípios de Jucati, Jupi e Lajedo.

O Município de Lajedo, situado na mesorregião do Agreste do Estado de Pernambuco, é destaque pela presença das unidades de produção de farinha da mandioca, cujo surgimento das primeiras unidades de beneficiamento, ocorreu, por volta da segunda metade do século passado, ainda, assim, aos moldes artesanais, em virtude do impulso do cultivo da mandioca bem característico naquela região. Apesar dessa importante cadeia produtiva, as casas de farinha em Lajedo carregam consigo desafios que ainda não foram superados, dentre eles, o atendimento às normas ambientais, sanitárias e trabalhistas (Barros Júnior; Souza; Araújo, 2016).

As casas de farinha em Lajedo possuem pessoas das mais diferentes faixas etárias no trabalho da fabricação da farinha, que, utilizam-se dos esforços físicos intensos, podendo acarretar diversos malefícios à saúde, tais como: estresses, queimaduras, amputações, cortes, dentre outros. O risco de malefícios à saúde é um indicador da situação de vulnerabilidade dos trabalhadores em casas de farinha. Os trabalhadores tornaram-se vulneráveis em determinado momento de suas vidas em razão de certas circunstâncias, sejam elas por meio de uma situação adversa, por falta de recursos e a dificuldade em adaptar se ao ambiente no qual estão inseridos.

Outrossim, a realidade da vulnerabilidade dos trabalhadores no ambiente de casas de farinha é consequência de uma condição desfavorável de vida e da ausência de condições básicas a esses indivíduos, por exemplo, baixa escolaridade dos trabalhadores e a baixa remuneração. A vulnerabilidade trata-se da exposição de indivíduos ou grupos ao estresse (mudanças inesperadas e rupturas nos sistemas de vida) resultante de mudanças socioambientais (Confalonieri 2001).

A vulnerabilidade pode ser analisada de diferentes pontos de vista, podendo ser um risco para um indivíduo isoladamente ou para um sistema exposto ao perigo e corresponde a sua predisposição intrínseca de ser afetado ou estar preparado para sofrer perdas. A vulnerabilidade, também, traduz a incapacidade de uma comunidade de absorver, através de seu próprio ajuste, os efeitos das mudanças ambientais (Barbosa 1997).

Neste sentido, o estudo da vulnerabilidade em casas de farinha é extremamente importante para que se possam implantar políticas públicas eficiente de sustentabilidade socioambiental nos referidos empreendimentos. Face ao exposto, o presente trabalho tem como objetivo quantificar o grau de vulnerabilidade dos trabalhadores nas casas de farinha no Município de Lajedo. 


\section{Material e MÉtodos}

\section{Caracterização da área de estudo}

De acordo com dados da Agência Estadual de Planejamento e Pesquisas de Pernambuco - CONDEPE/ FIDEM (2006), o Município de Lajedo encontra-se localizado na região de desenvolvimento do Agreste Meridional, na microrregião de Garanhuns e na mesorregião do Agreste Pernambucano (Figura 1).

\section{Figura 1 - Localização do Município de Lajedo no Agreste do Estado de Pernambuco}

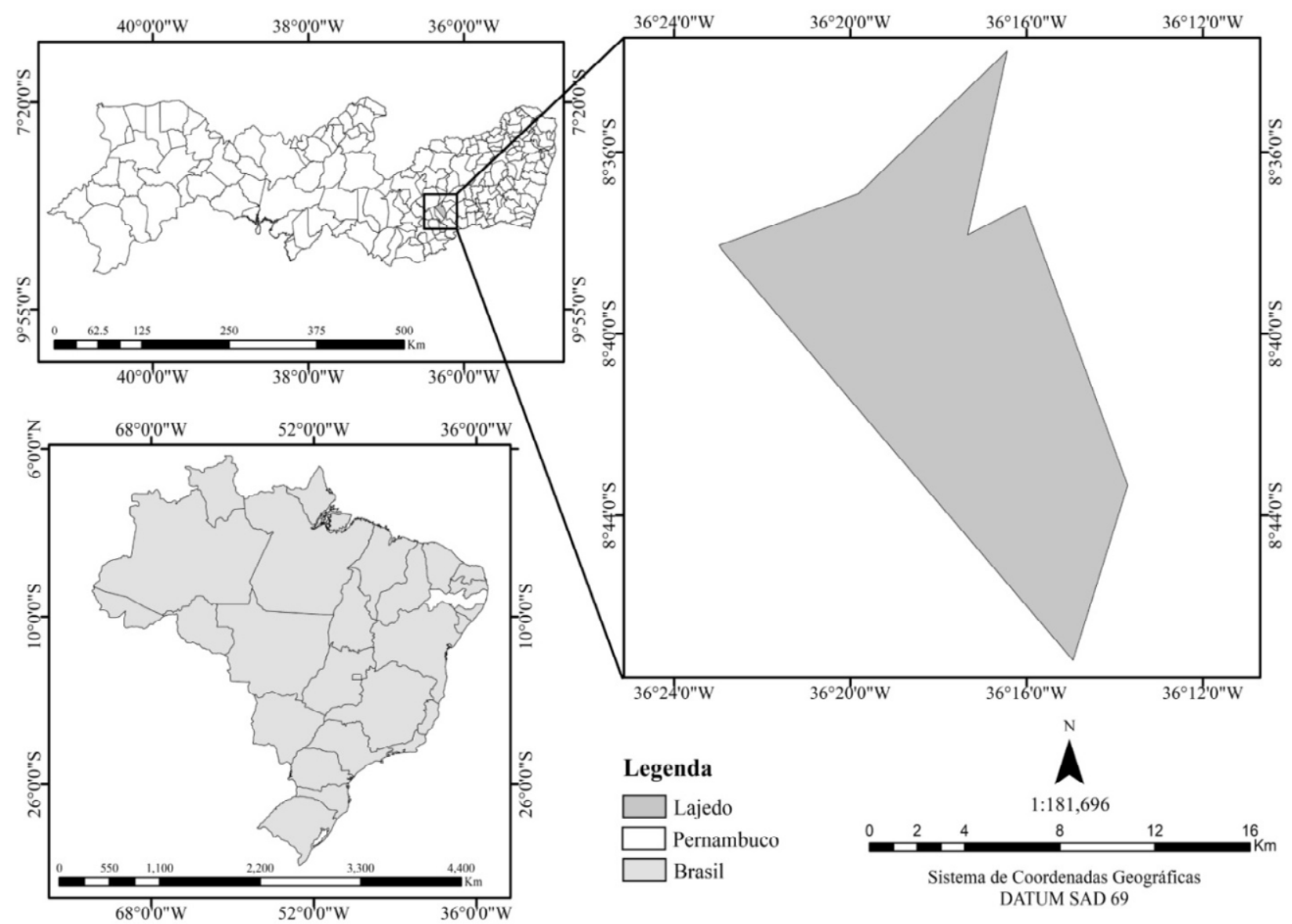

A área territorial do Município de Lajedo é de 189,55 $\mathrm{km}^{2}$ e possui os seguintes limites municipais: ao norte, os municípios de Cachoeirinha e São Bento do Una; ao sul, o de Canhotinho; ao leste, o de Ibirajuba; e a oeste, o de Calçado. Os povoados que integram o território municipal são Quatis, Santa Luzia, Imaculada, Cantinho e Pau Ferro (Condepe/Fidem 2006).

Segundo Dias (2013), o clima de Lajedo é do tipo tropical chuvoso, com verão seco, tendo média anual de $21^{\circ} \mathrm{C}$ a $24,5^{\circ} \mathrm{C}$, com duas estações do ano: o inverno e o verão. O Município de Lajedo encontra-se inserido nos domínios da Bacia Hidrográfica do Rio Una, tendo como principais tributários a margem direita: o riacho Quatis e o Rio Chata (Condepe/Fidem 2006).

Quanto aos aspectos geomorfológicos, pedológicos e vegetativo, o Serviço Geológico do Brasil - CPRM (2005, p.3) traz a seguinte informação:

O relevo é geralmente movimentado, com vales profundos e estreitos dissecados. Com respeito à fertilidade dos solos é bastante variada, com certa predominância de média para alta. A vegetação desta unidade é formada por Florestas Subcaducifólica e Caducifólica, próprias das áreas agrestes. 
De acordo com informações do Instituto Brasileiro de Geografia e Estatística - IBGE, no ano de 2017, a população estimada do Município de Lajedo foi de 39.888 habitantes, com uma densidade demográfica de 193,7 $\left(\right.$ hab $/ \mathrm{km}^{2}$ ). A agricultura é uma das principais atividades econômicas do município, com destaque para o cultivo do milho, feijão e da mandioca (Condepe/Fidem 2014).

O Município de Lajedo é conhecido no Estado de Pernambuco pela grande quantidade de casas de farinha espalhadas em seu território. No que concerne ao surgimento desses empreendimentos, o pesquisador Barros Júnior (2015, p.28-29) aduz:

No Município de Lajedo, no Agreste Meridional do Estado de Pernambuco, segundo relatos de proprietários das casas de farinha, por volta da segunda metade do século XX, surgiram às primeiras casas de farinha em razão da necessidade dos produtores de mandioca de beneficiar o referido tubérculo. As primeiras casas de farinha eram do tipo tradicional, ou seja, seu método de produção era completamente manual e compassadamente ocorreu à mecanização das casas de farinha, com a implantação da prensa hidráulica e do motor triturador, fato que contribuiu para que as unidades de beneficiamento da mandioca atingissem e mantivessem na atualidade o enquadramento no tipo modernizado.

É importante mencionar que ao longo da paisagem do Agreste da região do Município de Lajedo é comum visualizar a alta concentração do cultivo da mandioca e a quantidade de casas de farinha espalhadas em seu território. As casas de farinha surgiram no Município de Lajedo por uma necessidade dos agricultores que produziam e não tinham como realizar o beneficiamento do tubérculo em questão.

\section{Procedimentos metodológicos}

A fim de realizar o estudo de cunho exploratório, foi necessário o levantamento de dados a partir de fontes primárias e secundárias. Sobre o levantamento de dados, Gil (2002, p. 50-51) aduz:

O levantamento de dados caracteriza-se pela interrogação direta das pessoas cujo comportamento se deseja conhecer. Basicamente, procede a solicitação de informações a um grupo significativo de pessoas acerca do problema estudado para, em seguida, mediante análise quantitativa, obterem-se as conclusões correspondentes aos dados coletados. Quando o levantamento recolhe informações de todos os integrantes do universo pesquisado, tem-se um censo.

No que concerne às fontes primárias foi necessário visita às casas de farinha com aplicação de entrevista semiestruturada adaptado de Barbosa (1997) e Souza (2011) para ser aplicado junto aos trabalhadores em 17 (dezessete) casas de farinha (Tabela 1) e, voluntariamente, os pesquisados acordaram em permissão para a divulgação das informações. O período de investigação foi o mês de fevereiro de 2015. 
Tabela 1 - Localização das casas de farinha em Lajedo

Localização
Sítio Poço
Sítio Poço
Sítio Poço
Sítio Poço
Povoado Imaculada
Povoado Imaculada
Sítio Grosso
Sítio Grosso
Sítio Olho D’Água Novo
Sítio Olho D’Água Novo
Sítio Olho D’Água dos Pombos
Bairro Bom Jesus/zona urbana
Sítio Olho D’ Água Velho
Sítio Olho D’Água Velho
Sítio Lagoa do Meio
Povoado Bom Jesus I
Povoado Lagoa da Jurema
Total

\section{Coordenada UTM}

24 L 0795296/9039631

24 L 0795225/9039618

24 L 0795384/9039527

24 L 0795985/9039411

24 L 0798886/9039403

24 L 0798523/9039264

24 L $0796859 / 9036181$

24 L 0797525/9034899

24 L 0796170/9036625

24 L 0796050/9036203

24 L 0790624/9040865

24 L 0793464/9041839

24 L 0795209/9034388

24 L 0795606/9034938

24 L 0797762/9040010

24 L 0793687/9041494

24 L 0792366/9041649

\section{Casa de Farinha ${ }^{\circ}$}

01

02

03

04

05

06

07

08

09

10

11

12

13

14

15

16

17

17

\section{Quantidade de \\ Trabalhadores}

20

26

15

12

27

20

12

23

25

25

26

41

20

15

13

22

20

162

Dos 162 trabalhadores das casas de farinha (universo da pesquisa), foram aplicados 71 questionários junto aos trabalhadores, obtendo amostra em 19,6\%, valor aceitável e acima do índice mínimo recomendado de amostra em 10\%, tendo como base conceitos internalizados em estatística. A aplicação dos questionários foi realizada exclusivamente pelos autores do trabalho.

A partir da Tabela 1, constatou-se que algumas casas de farinha no Município de Lajedo encontram-se concentradas no Sítio Poço, Sítio Olho D’ Água Novo e Sítio Olho D’ Água Velho em virtude da proximidade das áreas de cultivo da mandioca, bem como a influência da rodovia PE 170, que liga os municípios de Lajedo ao de Canhotinho. A presença das casas de farinha próxima a essa rodovia estadual traz os seguintes benefícios: i) posição estratégica na "rede geográfica da farinha", tendo em vista, a facilidade do escoamento da produção de farinha; ii)abastecimento de matéria-prima - lenha e mandioca - para as casas de farinha e; iii) circulação de pessoas, dando visibilidade e a oportunidade de negócios.

$\mathrm{Na}$ entrevista semiestruturada foram analisadas as vulnerabilidades social, econômica e ambiental. $\mathrm{Na}$ determinação das vulnerabilidades, os dados foram tabulados a partir das respostas obtidas através dos questionários aplicados.

A tabulação consistiu em agrupar os dados, utilizando planilha eletrônica, os códigos encontrados em cada item das variáveis. Cada entrevista (item) foi tabulada individualmente e posteriormente foram feitos os gráficos da vulnerabilidade correspondente, conforme método adotado por Barbosa (1997) e Souza (2011). A determinação dos fatores da vulnerabilidade social, econômica e ambiental foi realizada a partir da seguinte equação: $\mathrm{V}=\mathrm{ax}+\mathrm{b}$ :

Em que: $\mathrm{V}=$ Fator Vulnerabilidade; $\mathrm{a}$ e $\mathrm{b}=$ constantes para cada variável;

$\mathrm{x}=$ valor significativo encontrado.

O Valor Significativo Encontrado (V) foi determinado, somando-se o valor da Moda, encontrada em cada item das variáveis. O Valor Mínimo, no caso, (x) foi determinado, somando-se o valor encontrado (codificação significativa de maior frequência) de cada item que compõe a variável do fator de vulnerabilidade.

$\mathrm{Na}$ determinação das vulnerabilidades, foi utilizada a classificação sugerida por Barbosa (1997), dividida em quatro classes, as quais variam de zero (vulnerabilidade nula) até 100\% (vulnerabilidade máxima). O referido autor propõe a seguinte classificação: Baixa (0-15\%); Moderada (16-30\%); Alta (31-45\%) e Muito Alta (> 45\%). 
É digno mencionar que, para dar concretude e operacionalidade a um conceito tão amplo como o da vulnerabilidade no ambiente de trabalho, é tarefa extremamente complexa, uma vez que só pode ser medida ao se observar o impacto de um acidente quando e onde ele ocorre, já que é específica para cada tipo de trabalho e para cada região e grupo de trabalhadores envolvidos. Apesar dessa complexidade, a realização das entrevistas permitiu a avaliação e a percepção dos trabalhadores frente aos impactos associados aos acidentes nas casas de farinha em Lajedo. No que se refere às fontes secundárias compreendeu o levantamento bibliográfico, a interpretação de dados cartográficos e a análise e organização dos dados a fim de subsidiar a elaboração do estudo científico.

\section{Resultados E Discussão}

No Brasil, existem diferentes graus de precariedade e vulnerabilidade ocupacional, que passa por quatro tipos de privação, a saber: o desemprego, o trabalho sem remuneração, a remuneração muito baixa e a falta de cobertura da previdência social. O mesmo informa sobre as estimativas de déficits relacionados com o conceito de trabalho decente, pois os problemas são crônicos e atingem parcelas expressivas dos trabalhadores e se manifestam em diferentes formas de inserção no mercado de trabalho (Proni 2011).

O estudo da vulnerabilidade dos trabalhadores nas casas de farinha em Lajedo tem o foco social, econômico e ambiental. Os trabalhadores tornaram-se vulneráveis, em determinado momento de suas vidas, em razão de certas circunstâncias sejam elas por meio de uma situação adversa, por falta de recursos e pela dificuldade de adaptar - se ao contexto no qual estão inseridos.

De acordo com Brooks (2003, p.08), o termo adaptação diz respeito "ao ajustamento no comportamento e nas características de um sistema para melhorar a sua capacidade de lidar com as tensões externas". Em diversos campos das ciências humanas, as adaptações são consideradas como respostas aos riscos associados com a interação de riscos ambientais e vulnerabilidade humana ou capacidade de adaptação (Smit; Wandel 2006).

No trabalho de campo verificou-se que as condições de trabalho nas casas de farinha em Lajedo são precárias (Figura 2), com baixa remuneração e escolaridade, bem como com longa jornada extenuante, situações essas que preconizam a vulnerabilidade ocupacional. Foram constatados cortes, arranhões, convívio com altas temperaturas, fumaças, poeiras, as cinzas da lenha e a contínua flexão inadequada do tronco pelos trabalhadores.

Figura 2 - Identificação das condições de trabalho nas casas de farinha em Lajedo: a) Trauma no dedo de trabalhador; b) Operário exposto ao pó da farinha da mandioca; c) Trabalhador flexionando o tronco e exposição às altas temperaturas; d) Uso intenso da força física por operário na prensa hidráulica e ausência de Equipamento de Proteção Individual (EPI).
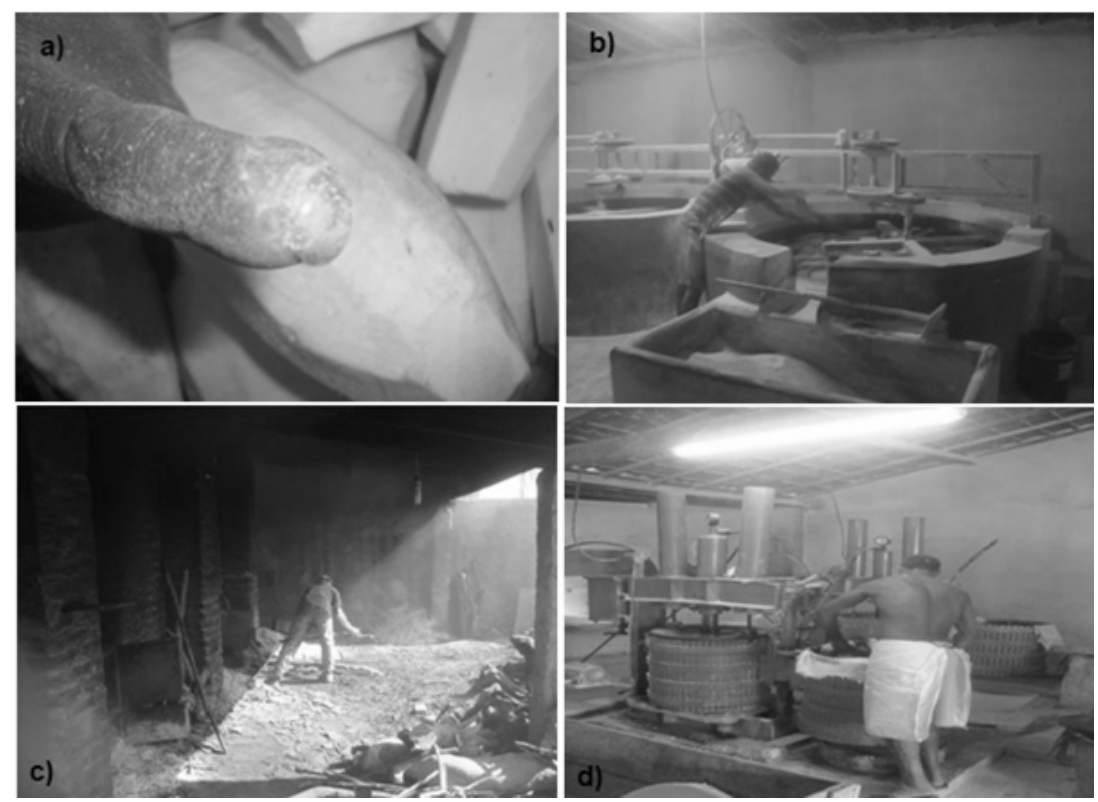
Diante do registro fotográfico, foi observado que durante o descascamento da mandioca atividade geralmente praticada pelas mulheres situações de cortes, arranhões e relatos de dores nas costas. Os homens, pelo aspecto virilidade, cumprem as tarefas que necessitam de maior esforço físico, por exemplo, alimentando os fornos com lenha e no manuseio das máquinas que ao longo do processo de beneficiamento da mandioca estão cobertos pelo pó da farinha, comprometendo sua saúde, sobretudo com problemas respiratórios.

No dizer de May (2010), o setor industrial é um dos que mais provocam danos ao meio ambiente, seja por seus processos produtivos ou pela fabricação de produtos poluentes e/ou que tenham problemas de disposição final após sua utilização. Nesse contexto, a lógica de acumulação e expansão da indústria de farinha se dá pela promoção de impactos ambientais pautados na extrema vulnerabilidade social e econômica dos trabalhadores das casas de farinha, que se desenvolvem para expansão do capital.

A ausência de uma boa ventilação, máscaras de proteção, falta de condução do ar quente fazem parte da rotina nas casas de farinha lajedense. Não existe controle de temperatura dos fornos, ocorrendo o desperdício no uso da lenha, principal meio energético desses empreendimentos.

No que tange aos cuidados com o calor, cumpre mencionar a especificidade trazida por Costa e Costa (2004, p. 94):

Limitar a exposição, com intervalos regulares de trabalho; incorporar um sistema de climatização do ar; controlar as fontes geradoras e de transmissão de calor, através de barreiras; disponibilizar água e soluções hidratantes nos arredores do local; disponibilizar EPIs adequados, em função das tarefas realizadas; realizar avaliações médicas periódicas; realizar programas de treinamento em primeiros socorros e de identificação de sintomas relativos a este agente de risco.

Além de todas essas enfermidades e deformações, há outros fatores que causam grandes danos físicos aos operários. O trabalho em meio às máquinas está sujeito a numerosos acidentes mais ou menos graves cuja consequência é a incapacidade parcial ou total do operário para seu trabalho (Engels 2010).

Conforme se detrai das palavras do autor, a interação do homem com as máquinas podem provocar condições danosas para a segurança e saúde dos trabalhadores. Destarte, a ausência de medidas no sentido de eliminar ou neutralizar os riscos da atividade nas unidades de beneficiamento da mandioca pode conferir graves problemas aos indivíduos que lidam no referido trabalho. Peniche (2014) comenta que os trabalhadores das casas de farinha desenvolvem suas práticas, estando, diariamente expostos a riscos a sua saúde.

A análise das vulnerabilidades social, econômica e ambiental, realizada através do trabalho de campo, por meio da aplicação de entrevista semiestruturada (Figura 3), permitiu diagnosticar o quadro socioeconômico e ambiental dos trabalhadores nas casas de farinha em Lajedo, cujo valor encontrado para vulnerabilidade social se encontra em 65,15\% (Figura 3a), indicando que os trabalhadores encontram-se expostos a uma Vulnerabilidade Social Muito Alta. 
Figura 3 - Fator vulnerabilidade A) social, B) econômica e C) ambiental.

A)

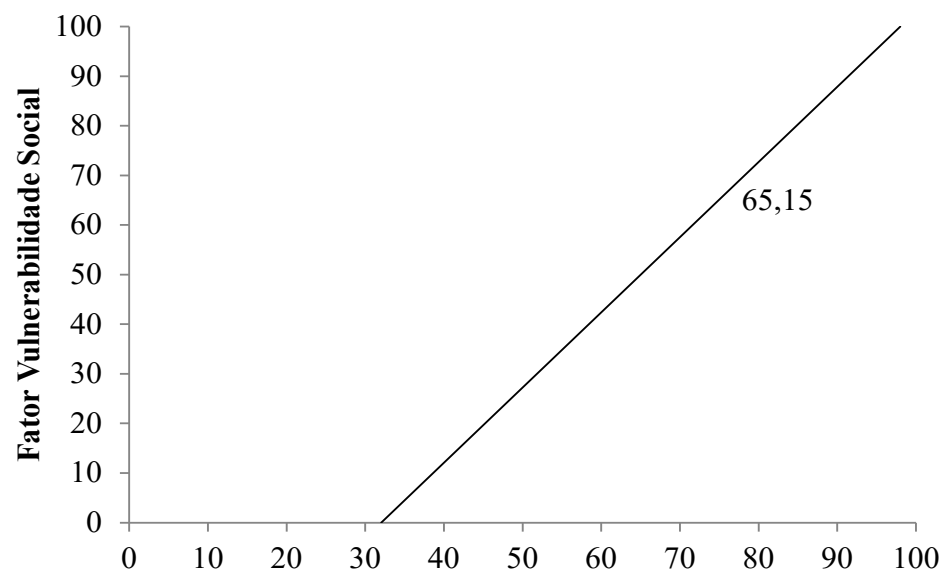

B)

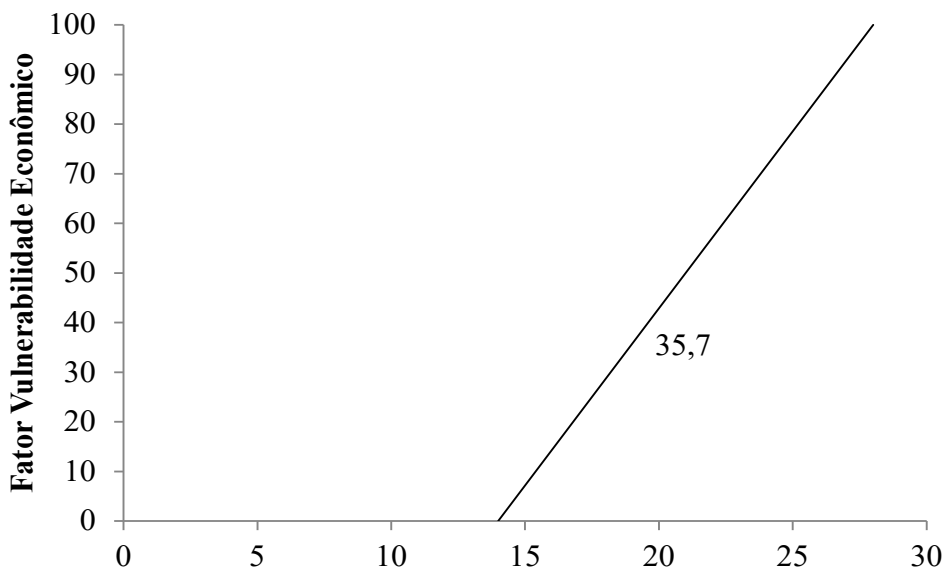

C)

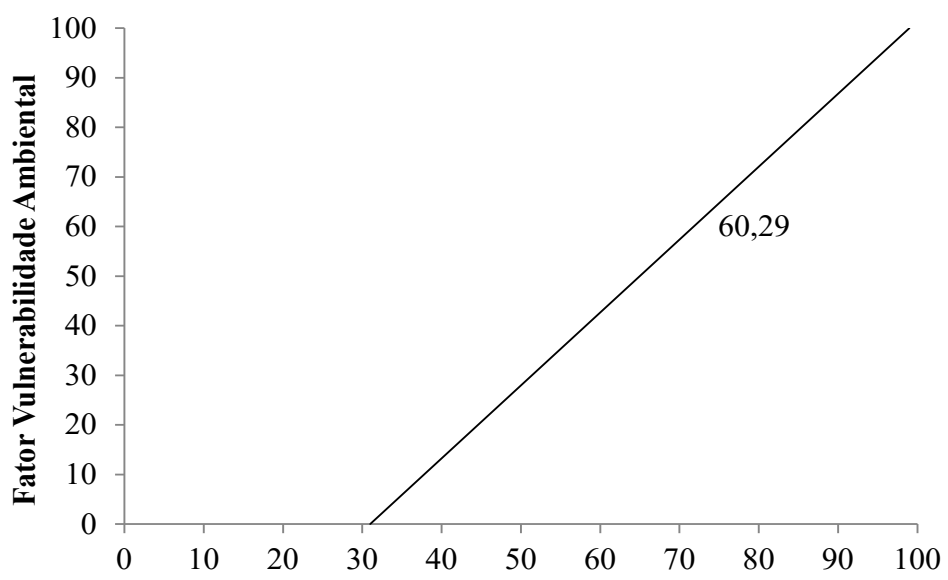

Este resultado remete às condições que são impostas às pessoas que trabalham nas casas de farinha no município de Lajedo, bem como das complexidades das condições de vida dessas pessoas associado à falta de políticas públicas que atendam efetivamente as necessidades desses trabalhadores em se manterem de forma sustentável.

O principal indicador da vulnerabilidade social diz respeito à variável educação, em sua maioria constituída por analfabetos e ensino fundamental incompleto. Verificando-se que o grau de escolaridade dos entrevistados é bem abaixo do desejado, como consequência, a falta de instrução impossibilita o acesso dos trabalhadores a melhor colocação no mercado de trabalho.

O perfil dos trabalhadores se concentra na faixa etária de 25 a 30 anos, com residência fixa na zona rural, revelando que a mão-de-obra é oriunda do entorno da casa de farinha. Na zona rural é desprovido do serviço público de coleta de resíduo sólido domiciliar o que favorece a prática por parte dos entrevistados de enterrar e queimar o lixo. É um indicador de vulnerabilidade e revela um dado preocupante pelo índice de pessoas que declararam cometer tal prática, pois é um material sólido, sem tratamento nenhum, estando solto na natureza, 
alterando a paisagem, os constrangimentos com mau cheiro, possibilidade de patologias (verminoses, micoses, dentre outras). A ausência do poder público no saneamento básico revela as mazelas pelas quais passam essas pessoas.

Ao ser questionado sobre os efluentes domésticos ou sobre o esgoto sanitário, 15,5\% dos entrevistados afirmaram que a eliminação é livre. É um dado alarmante e carece a construção de redes de saneamento, a fim de reduzir os riscos de doenças ligadas à insalubridade. Constata-se que a exposição dessas pessoas ao estresse, ao risco e à fragilização no determinado contexto de vida ratifica que estão inseridas em uma vulnerabilidade social.

Philippi Jr e Malheiros (2005, p. 75) citam que:

Nos países em desenvolvimento, os indicadores de desenvolvimento social e ambiental não atingiram ainda patamares adequados de atendimento das ações de saneamento do meio, inclusive com profundas diferenças no que se refere à universalidade do atendimento, principalmente por causa da ausência de políticas para a área de saúde pública.

Para a vulnerabilidade econômica, o valor determinado foi de 35,7\%, (Figura 3b), indicando que os trabalhadores encontram-se expostos a uma Vulnerabilidade Econômica Alta. Esse dado se reflete nas declarações dos entrevistados, ao mencionarem o programa governamental de transferência direta de renda que beneficia famílias em situação de pobreza, conhecido por bolsa família, tem garantido o acesso à educação dos filhos dos trabalhadores das farinheiras. O programa bolsa família é uma iniciativa do Governo Federal de distribuição de renda direcionado as famílias brasileiras economicamente mais vulneráveis na sociedade, contribuindo para o acesso dessas pessoas de baixa renda a bens e serviços básicos como, por exemplo, educação, alimentação e pagamento da água e luz.

Para a vulnerabilidade ambiental, o valor encontrado foi de 60,29\%, (Figura 3c), representando que os trabalhadores são carentes e encontra-se com Vulnerabilidade Muito Alta, indicando o quanto este tipo de atividade é associado a riscos e acidentes, pois são os trabalhadores que sofrem diretamente os efeitos negativos decorrentes de um trabalho insalubre e precário. Vale ressaltar que a vulnerabilidade acima de $45 \%$ é inaceitável, conforme Barbosa (1997).

Segundo Jordão e Moretto (2015), a vulnerabilidade ambiental é fundamental para compreensão da sustentabilidade e viabilidade das atividades humanas. Quanto à exposição das pessoas que trabalham nas casas de farinha, os autores Almeida e Lins (2013, p.1) citam que:

Na cultura de mandioca, há 70 mil crianças, mas o trabalho mais arriscado é nas casas de farinha, como as do interior de Pernambuco. Glória do Goitá fica no limite com o Agreste. É possível flagrar crianças em três de quatro estabelecimentos visitados, onde meninos, na maioria, trabalham expostos ao pó, ao barulho dos motores, ao calor dos fornos e ao cheiro forte da manipueira, substância de alto teor alcoólico liberada no processamento da mandioca. Nenhum deles foi visto pela equipe do Globo com qualquer equipamento de proteção.

Verifica-se que os trabalhadores das casas de farinha estão expostos aos seguintes riscos físicos; calor e ruído, este último podendo levar à perda auditiva; químicos (manipueira); biológicos; ergonômicos; e a acidentes. Fica evidente que tais riscos ambientais podem comprometer a saúde e a integridade física destas pessoas.

Ainda assim, os homens que manuseiam as máquinas de prensar declararam o incômodo com o ruído e com o forte odor da manipueira, líquido que sobra da prensagem da mandioca de elevadíssima carga orgânica e de ácido cianídrico, que tem provocado náuseas e dores de cabeça nos trabalhadores. Zacarias (2011) em minucioso estudo em quatro casas de farinha localizadas no Agreste Alagoano, microrregião de Arapiraca concluiu que os 
trabalhadores estão expostos cronicamente ao ácido cianídrico (HCN) devido à liberação deste gás durante o processamento da mandioca e que pode resultar na ocorrência de efeitos adversos à saúde dos trabalhadores.

Constata-se que os trabalhadores nas casas de farinha, em Pernambuco, estão vulneráveis a diferentes riscos ocupacionais, com baixa remuneração onde as crianças trabalham como adultos a fim de complementar a renda da família. Nesse sentido, Haug (1997, p.149) faz a seguinte reflexão:

A classe trabalhadora defronta-se com o capital não somente como classe explorada na produção e criadora de todos os valores, mesmo dos valores que são a fonte de todas as formas de lucro e excedente social; a classe trabalhadora confronta-se também, como massa de compradores, com as partes do capital social total que produzem, no sentido mais amplo, os meios de sobrevivência necessários.

Eis o que Souza (2011, p.7-8) aduz acerca da correlação da vulnerabilidade e riscos em relação ao sistema capitalista, a saber:

A compreensão da vulnerabilidade, que é uma componente inseparável de um desastre, é vital para reduzir os efeitos negativos das catástrofes sobre uma sociedade. A vulnerabilidade é uma característica essencialmente humana, que está diretamente associada com a produção dos espaços, com a organização do trabalho e da produção, cujas condições sociais, econômicas e ambientais são as respostas diretas de um desastre. Na realidade, são as relações capitalistas - as principais causas das vulnerabilidades e dos riscos, pelo empobrecimento de grande parte da população pela exploração do trabalho, o acúmulo de capital e a concentração de renda por um pequeno grupo. Infelizmente, os grupos mais vulneráveis aos riscos a desastres são os mais pobres, devido à situação econômica para absorver o impacto dos desastres e recuperar-se dos seus efeitos. A vulnerabilidade à desastres refere-se à incapacidade das pessoas, sociedades e organizações para suportar os efeitos negativos a partir de múltiplos estresse a que estão expostos.

O pesquisador Cardona (2001) propõe os seguintes fatores pelos quais se origina a vulnerabilidade:

a) Fragilidade física ou exposição: trata-se da condição de susceptibilidade do grupo populacional de ser afetado por um fenômeno perigoso, em virtude de estar inserida na área de influência do mesmo e por causa da falta de resistência física a sua propagação.

b) A fragilidade social: refere-se à predisposição de um grupo populacional por estar num nível de marginalidade, segregação e fragilidade socioeconômica de sofrer danos em face de um fenômeno perigoso.

c) A falta de resiliência: expressa as limitações de acesso e mobilização de recursos do ser humano, sua incapacidade de resposta e suas deficiências para absorver o impacto.

Diante do exposto acima, os trabalhadores em epígrafe acham-se em uma situação de vulnerabilidade por conta das péssimas condições do trabalho e pela incapacidade desses indivíduos de adaptar-se às situações hostis do trabalho. A falta de planejamento nas casas de farinha favorece o desenvolvimento das situações vulneráveis possibilitando, assim, a ocorrência dos acidentes no trabalho.

Barros Júnior e Pacheco (2012, p.22) no estudo diagnóstico das casas de farinha nos municípios de Lajedo, Jupi e Jucati mencionam que "[...] o meio ambiente são os trabalhadores, a qualidade de vida destas pessoas, o uso do equipamento de proteção individual, dentre outros". Costa e Costa (2004, p. 3) informam que "de acordo com a legislação brasileira, é obrigação das empresas adotarem medidas de prevenção e controle de doenças ocupacionais e acidentes do trabalho".

Apesar dos questionários não retratarem as reais dimensões dos problemas associados ao ambiente de trabalho numa casa de farinha, refletem de alguma forma a vulnerabilidade do ser humano frente ao trabalho penoso, 
insalubre e propício a acidentes de trabalho e doenças ocupacionais. Ainda assim, são pessoas que estão inseridas numa sociedade excludente e que impera a lógica capitalista da má distribuição de renda, acarretando na destruição das famílias, tornando-se vulneráveis, pois muitas vezes a omissão do Estado em políticas sociais deixa as famílias sobrecarregadas e estas não conseguem romper o ciclo, pois estão vulneráveis social e economicamente.

Destarte, o fomento de políticas públicas que oportunizem aos proprietários das casas de farinha atender às normas ambientais, sanitárias e trabalhistas é fundamental para uma mudança de paradigma. Sen (2010, p. 349) aduz:

Para a elaboração de políticas públicas é importante não apenas avaliar as exigências de justiça e o alcance dos valores ao se escolherem os objetivos e as prioridades da política pública, mas também compreender os valores do público em geral, incluindo seu senso de justiça.

Outro agravante para a continuidade da vulnerabilidade dos trabalhadores nas casas de farinha em Lajedo é a falta de educação, o que pode prolongar tal problemática por mais algumas gerações, tendo em vista que a baixa escolaridade proporciona ao homem a falta de autonomia para tomada de decisões, fazendo com que permaneça à mercê de qualquer trabalho, pois é necessário garantir, de forma honesta, o prato de comida para si e para seus dependentes, geralmente crianças e recém-nascidos.

\section{Conclusão}

Os altos índices de vulnerabilidade encontrados são relacionados às fortes limitações socioeconômicas e ambientais, as quais são comprometidas pela ausência de políticas públicas que amenizem a carência dos trabalhadores, sendo intensificados pelas más condições de funcionamento das casas de farinha, geralmente, em desacordo com as normas ambientais, sanitárias e trabalhistas.

A vulnerabilidade social dos trabalhadores que labutam nas casas de farinha no Município de Lajedo foi considerada Muito Alta. Esse resultado reflete as péssimas condições de vida em que essas pessoas estão inclusas, o modelo predominante na sociedade brasileira e mundial, no caso, o sistema capitalista. Infelizmente, esses trabalhadores vivem em uma situação de pobreza, com baixa escolaridade e sem perspectiva de um futuro promissor. A falta de educação oportuniza que os trabalhadores não possam almejar melhores colocações no mercado de trabalho e, sem autonomia de decisão, estão à mercê de um trabalho insalubre e precário.

No que concerne à vulnerabilidade econômica foi apontado como Alta, representando a baixa renda dos trabalhadores, que vem a corroborar que precocemente pessoas de menos idades (adolescentes e crianças) ingressem no trabalho da farinhada para garantir uma renda extra à família.

A vulnerabilidade ambiental dos trabalhadores nas casas de farinha no Município de Lajedo foi avaliada como Muito Alta. Tal situação se reflete a ausência do uso dos Equipamentos de Proteção Individual (EPIs) pelos trabalhadores, bem como a precariedade das condições de funcionamento destes empreendimentos. Constata-se o quanto essa atividade estar relacionada a riscos, acidentes e doenças ocupacionais por parte dos trabalhadores em virtude de um ambiente de trabalho inadequado.

De modo geral as casas de farinha possuem a vulnerabilidade global muito alta. Estes números traduzem aos riscos, acidentes e doenças ocupacionais por parte dos trabalhadores em virtude de um ambiente de trabalho inadequado.

As casas de farinha em Lajedo encontram - se em situação de vulnerabilidade em virtude da carência de representação política, da educação ambiental e da falta de uma cooperativa que represente e fortaleça os proprietários das casas de farinha. Provavelmente, o cooperativismo permitiria maior benefício fiscal, bem como o 
aumento da competitividade para os pequenos proprietários das casas de farinha que vivem isolados e com menos condições de enfrentar o mercado.

\section{Agradecimentos}

Aos proprietários e trabalhadores das casas de farinha do Município de Lajedo, principais atores desta pesquisa. E ao Programa de Pós - Graduação em Desenvolvimento e Meio Ambiente - PRODEMA da Universidade Federal de Pernambuco - UFPE pelo suporte técnico e arcabouço teórico para realização deste trabalho.

\section{REFERÊNCIAS}

Almeida C, Lins L. 2013. Trabalho infantil no país expõe a risco 1,9 milhão de brasileiros. O Globo. Disponível em: <http:// oglobo.globo.com/economia/trabalho-infantil-no-pais-expoe-risco-19-milhao-de-brasileiros-8566109>. Acesso em: 21 abr. 2014.

Andrade MC. de. 2011. A terra e o homem no nordeste: contribuição ao estudo da questão agrária no Nordeste, 8. ed., São Paulo: Cortez, 334 p.

Barbosa MP. 1997. Vulnerabilidade de risco a desastre, Campina Grande: Departamento de Engenharia Agrícola/UFPB, 87 p.

Barros Júnior AP. de. 2015. Impactos ambientais da vulnerabilidade dos trabalhadores nas casas de farinha no agreste pernambucano. 2015. 133 f. Dissertação (Mestrado em Desenvolvimento e Meio Ambiente) - Universidade Federal de Pernambuco. Recife.

Barros Júnior AP. de., Pacheco ADC. 2012. Estudo diagnóstico das casas de farinha nos municípios de Lajedo, Jupi e Jucati, mesorregião do agreste meridional, do estado de Pernambuco. Revista Ensino \& Pesquisa, 2, 15-24 p.

Barros Júnior AP. de., Souza WM. de., Araújo, M. do. SB. de. 2016. Desenvolvimento e políticas públicas em unidades de produção de farinha da mandioca, Gaia Scientia, 10, 3, 26-35 p.

Barros Júnior AP. de., Pacheco ADC., Cardoso, JJ. 2016. Resíduos sólidos e líquidos em unidades de produção de farinha de mandioca. In: El-Deir, SG; Pinheiro SMG; Aguiar WJ. de. (Org.). Resíduos sólidos: práticas para uma gestão sustentável. 1. ed. Recife: EDUFRPE, 397-406 p.

Brooks N. 2003. Vulnerability, risk and adaptation: a conceptual framework. Working Paper 38. Tyndall Centre for Climate Change Research, 16 p. Disponível em: <http://www.tyndall.ac.uk/sites/default/files/wp38.pdf>. Acesso em: 14 maio 2016.

Camargo, CED. 1985. Mandioca o "pão caboclo": de alimento a combustível, 2. ed., São Paulo: ICONE, 66p.

Cardona OD. 2001. La necesidad de repensar de manera holística los conceptos de vulnerabilidad y riesgo: una crítica y una revisión necesaria para la gestión, Bogotá: Centro de Estudios sobre Desastres y Riesgos - CEDERI, 18 p.

Cascudo L. da C. 2011. História da alimentação no Brasil, 4. ed., São Paulo: Global, 960 p. 
Condepe/Fidem, Agência Estadual de Planejamento e Pesquisas de Pernambuco. 2006. CONDEPE/FIDEM. Bacias Hidrográficas do Rio Una, GL 4 e GL 5, Recife. 85 p. (Série Bacias Hidrográficas de Pernambuco, 3).

2014. Lajedo: perfil municipal. 2014. Disponível em: <http://www.bde.pe.gov.br/ArquivosPerfilMunicipal/ LAJEDO.pdf>. Acesso em: 03 abr. 2015.

Confalonieri UEC. 2011. Global environmental change and health in Brazil: review of the present situation and proposal for indicators for monitoring these effects. In: Human dimensions of global environmental change - Brazilian Perspectives, Rio de Janeiro: Academia Brasileira de Ciências, 43-77 p.

Costa MAF. da., Costa M. de FB. 2004. Segurança e saúde no trabalho, Rio de Janeiro: Qualitymark Editora, 197 p.

Dias PH. 2013. Lajedo: uma história de lutas, conquistas e glórias, Recife: Ed. do Autor, 138 p.

Engels F. 2010. A situação da classe trabalhadora na Inglaterra, Tradução Bernhardt A. Schumann, São Paulo: Boitempo, $388 \mathrm{p}$.

Gil AC. 2002. Como elaborar projetos de pesquisa, 4. ed., São Paulo: Atlas, 176 p.

Haug WF. 1997. Crítica da estética da mercadoria, Tradução de Erlon José Paschoal; Colaboração Jael Glauce da Fonseca, São Paulo: Fundação Editora da UNESP, 210 p.

Ibge, Instituto Brasileiro de Geografia e Estatística. 2017. Pernambuco - Lajedo: panorama-população. Disponível em: $<$ https://cidades.ibge.gov.br/brasil/pe/lajedo/panorama>. Acesso em: 21 abr. 2018.

Jordão C. de O., Moretto EM. 2015. The environmental vulnerability and the territorial planning of the sugarcane cultivation. São Paulo: Ambiente \& Sociedade, XVIII (1): 75-92 p. Disponível em: <http://www.scielo.br/pdf/asoc/v18n1/1414753X-asoc-18-01-00075.pdf>. Acesso em: 14 maio 2016.

MARCENA, Adriano. 2012. Mexendo o pirão: importância sociocultural da farinha de mandioca no Brasil holandês (1637-1646), Recife: Funcultura, 160 p.

May PH. (Org.). 2010. Economia do meio ambiente, 2.ed., Rio de Janeiro: Elsevier, 379 p.

Peniche, LR. da. S. 2014. O processo de trabalho na produção de farinha de mandioca no município de Rio BrancoAC: contribuições para vigilância em saúde do trabalhador. 2014. 96 f. Dissertação (Mestrado em Saúde Pública) Escola Nacional de Saúde Pública Sérgio Arouca. Rio de Janeiro.

Philippi Jr A.; Malheiros TF. 2005. Saúde ambiental e desenvolvimento. In: Educação ambiental e sustentabilidade..., Barueri: Manole, 59-83 p.

Proni MW. 2011. Trabalho decente e vulnerabilidade ocupacional no Brasil, Campinas: IE/UNICAMP,188, 26 p.

Sena M. das GC. de. 2006. Aspectos Sociais. In: Aspectos socioeconômicos e agronômicos da mandioca..., Cruz das Almas: Embrapa Mandioca e Fruticultura Tropical, 91-111 p.

Sen A. 2010. Desenvolvimento como liberdade, Tradução de Laura Teixeira Motta, revisão técnica Ricardo Doninelli Mendes, São Paulo: Companhia das Letras, 461 p. 
Serviço Geológico do Brasil. 2005. CPRM. Diagnóstico do município de Lajedo, estado de Pernambuco, Recife: CPRM/PRODEEM, 21 p. Disponível em: <http://rigeo.cprm.gov.br/xmlui/bitstream/handle/doc/16471/Rel_Lajedo. pdf?sequence=1>. Acesso em: 22 maio. 2018.

Smit B, Wandel J. 2006. Adaptation, adaptive capacity and vulnerability. Global Environmental Change, 16, $282-292$ p. Disponível em: <http://www.uio.no/studier/emner/annet/sum/SUM4015/h08/Smit.pdf>. Acesso em: 14 maio 2016.

Soares MOS. 2007. Sistema de produção em casas de farinha: uma leitura descritiva na comunidade de Campinhos - Vitória da Conquista (BA). 2007. 96 f. Dissertação (Mestrado em Desenvolvimento e Meio Ambiente) - Universidade Estadual de Santa Cruz, Ilhéus.

Souza WM. de. 2011. Impactos socioeconômicos e ambientais dos desastres associados às chuvas na cidade do Recife-PE. 2011. 121 f. Tese (Doutorado em Recursos Naturais) - Universidade Federal de Campina Grande, Campina Grande.

Zacarias CH. 2011. Avaliação da exposição de trabalhadores de casas de farinha ao acido cianídrico proveniente da mandioca, Manihot esculenta, Crantz, no agreste alagoano. 2011. 147 f. Dissertação (Mestrado em Toxicologia e Análises Toxicológicas) - Universidade de São Paulo, São Paulo. 